\title{
Международные принципы в сфере управления публичными финансами: новая инициатива России
}

\author{
ЦЦзян В.ШІ.
}

Летом 2006 г. Министерство финансов Российской Федерации в рамках председательства Российской Федерации в «Группе восьми» выступило с инициативой повысить роль предпринимаемых на международном уровне усилий по содействию эффективному и ответственному управлению публичными (государственными и муниципальными) финансами.

Исходя из накопленного за последние годы коллективного опыта в области управления общественными финансами, включая результаты бюджетных реформ, Россия предложила шире применять общепризнанные стандарты и критерии эффективного и ответственного управления публичными финансами.

В рамках этой инициативы предлагается:

- согласовать общее понимание основного содержания принципов эффективного и ответственного управления публичными финансами;

- на этой основе подготовить Кодекс надлежащей (лучшей) практики управления публичными финансами, а также соответствуюшцие стандарты и правила по его применению и использованию.

Чем продиктована эта инициатива России?

Как известно, одной из основных тенденций развития мирового сообщества на современном этапе является глобализация. Наиболее интенсивно процессы глобализации протекают в сфере экономики, проявляясь в активном формировании единого мирового экономического пространства. Аналогичные процессы наблюдаются и в других сферах общественной жизни, в том числе и в праве. Глобализация правового пространства способствует созданию единого правового поля, нивелируя особенности национальных законодательств.

Идея создания единого мирового правопорядка не нова. В 1900 г. на Международном конгрессе сравнительного права, проходившем в Париже в рамках Всемирной выставки, Э. Ламбер предложил разрабо-

* Цзян В.Ш. - соискатель МГИМО (МИД) России. 
тать через сравнительный анализ национальных правовых систем так называемое вселенское право, единое для всего человечества. Последугщие мировые войны существенно подорвали веру в возможность его создания. Но в свете глобализационных процессов нового тысячелетия предложение Э. Ламбера выглядит не столь уж утопичным.

Преобразования, проводимые в России на протяжении последних лет, с очевидностью свидетельствуют о стремлении нашей страны к интеграции в мировое экономическое пространство. Уже сегодня Россия в известной степени зависит от глобальных потоков капиталов, товаров, технологий, информации и т.д. Для далынейшего вхождения в мировой рынок требуется рештение ряда проблем, из которых особо выделим проблему гармонизации российского права с правопорядками ведущих экономически развитых стран и международных институтов и организаций. Ее решение видится прежде всего в использовании унифицированных норм в процессе националыного законотворчества и правоприменения.

Особое значение приобретает унификация норм материального права. Именно они, единообразно регулируя общественные отношения, обеспечивают единый правовой режим и позволяют создать единое правовое пространство. На это указывает и усиление их роли по сравнению с коллизионными нормами. Так, опыт стран Европейского союза показывает, что в сфере материалыного права коллизионное право вытесняется так называемым вторичным правом ЕС (регламенты, директивы, решения, рекомендации и заключения, принимаемые Европарламентом совместно с Советом). Обеспечивая единый правовой режим, унификация материалных норм также способствует сбллжению правовых систем.

В последние годы многими странами были приложены серьезные усилия по модернизации системы управления публичными финансами. В странах «Группы восьми» новые подходы предусматривают усиление внимания к проведению ответственной бюджетно-налоговой политики, средне- и долгосрочному бюджетному планированию в целях обеспечения финансовой стабильности и эффективности государственных расходов и повышению ответственности за результаты использования средств налогоплателыщиков. В частности, в России, которая находилась в более сложных условиях переходной экономики, этот процесс начинался с восстановления эффективного бюджетноналогового контроля и финансовой стабильности, а с начала 2000-х 
годов переключился на комплексную модернизацию системы управления публичными финансами, включающей создание Стабилизационного фонда, проведение налоговых реформ, формирование новой системы межбюджетных отношений и внедрение среднесрочного бюджетирования, ориентированного на результаты.

Что уже достигнуто на пути повьшения эффективности публичньх финансов?

В последние годы масштабная и впечатляющая работа практически по всем направлениям унификации права была проделана международными организациями, заинтересованными в ответственном и эффективном управлении публичными финансами, Межлународным валютным фондом, Всемирным банком и ОЭСР, а также на региональном уровне, например Азиатским банком развития (АзБР).

Страны «Группы восьми» приняли участие в работе в сфере публичных финансов, проведенной Международным валютным фондом (МВФ), Всемирным банком, Организацией экономического сотрудничества и развития (ОЭСР) и другими международными организациями по подготовке аналитических и методических материалов, кодексов и руководств, а также мониторингу достигнутого прогресса и оказанию соответствующей технической помощи. На основе накопленного к настоящему времени практического опыта сформулированы многие ставшие общепризнанными принципы, стандарты и критерии, которые представляют собой надежную основу для дальнейшего прогресса в сфере управления общественными финансами.

Европейский союз (ЕС) ввел ряд конкретных правил в отношении бюджетно-налоговой ответственности в рамках Пакта о стабильности и экономическом росте и введения евро в качестве единой валюты для некоторых своих членов. Принятые им правила (acquis communautaire) в области финансового контроля также имеют обязательное действие для членов ЕС. В Содружестве наций достигнуто соглашение о правилах проведения реформы в области управления публичными финансами. Страны-доноры разработали руководства для применения их на национальном уровне, предназначенные для использования при оказании технического содействия или предоставления бюджетной поддержки странам с переходной или развивающейся экономикой. Правительства некоторых стран или их министерства финансов также разработали принципы для собственного использования. В Лимской декларации установлены международно признанные прин- 
ципы аудига.

Проделанная работа позволяет сгруппировать унифицированные нормативные документы, направленные на повышение эффективности использования публичньх финансов, в несколько групп ${ }^{1}$.

А. Обязательные для исполнения нормативные требования

- Процедура Европейского союза в отношении чрезмерного дефицита, включая нормы, утвержденные статьями 9 и 104 Договора Европейского союза и уточненные Положением Совета ЕС № 1055/2005 от 27 июоя 2005 г., вносящая поправки в «Пакт о стабильности и экономическом росте» от 1997 г. Эти нормы в первую очередь затрагивают некоторые параметры, имеющие отношение к финансовой ответственности, и приняты в качестве обязательных странами - членами ЕС; при этом они имеют особое значение для стран, входящих в зону евро.

- Правила финансового контроля ЕС в отношении присоединившихся стран, являготся еще одним примером обязательных норм, затрагивающих не только использование бюджетных средств ЕС, но и национальные бюджеты, поскольку условием вступления в ЕС было распространение действия единьх правил в отношении обоих уровней.

Такого рода взаимные формальные обязательства в отношении финансовой ответственности и надлежащего управления публичными финансами были необходимы в конкретных условиях ЕС, однако они являются исключением в современной международной практике и далее не рассматриваются².

Б. Официально принятые Кодексы лучшей (надлежащей) практики

- Кодекс надлежащей практики по обеспечению прозрачности в бюджетно-налоговой сфере МВФ (пересмотренный 28 февраля 2001 г.) является одним из принятых на международном уровне Стандартов и кодексов, мониторинг которых осуществляет Форум по финансовой стабильности. Благодаря этому он пользуется широкой международной поддержкой.

- Оптимальная практика по обеспечению прозрачности бюджета ОЭСР (обновлена в 2001 г.) была формально одобрена странами - членами ОЭСР и является общедоступным документом о надлежащей практике по обеспечению прозрачности бюджета.

- Лимская декларация о руководяших принципах аудита, принятая членами Международной организации высших органов финансового

${ }^{1} \mathrm{CM},:$ http://www.prime-tass.ru/analytics/files/documents/minfing8.pdf.

${ }^{2}$ CM.: http://europa.eu/index_en.htm 
аудита (1977 г.), содержит изложение согласованных принципов в отношении проведения независимого аудита публичных финансов, а также соответствующих методов работы.

- Руководяпце принципы осуществления реформы управления публичными финансами Содружества наций (2005 г.) предлагают некоторые принципы, которые должны учитываться при реформировании системы управления публичными финансами, а также содержат предложения по осуществлению этих реформ.

В. Рекомендации по надлежащей практике ответственного и эффективного управления публичными финансами

- Руководство МВФ по обеспечению прозрачности в бюджетноналоговой сфере (апрель 1999 г.) содержит принципы по обеспечению прозрачности в бюджетно-налоговой сфере, а также большое количество ссылок на иные источники, посвященные двум другим аспектам эффективного управления общественными финансами. МВФ также подготовил целый ряд документов, касаюшихся эффективной и ответственной бюджетно-налоговой политики (включая вопросы, возникающие в связи с «бюджетно-налоговым пространством для содействия экономическому росту»), в том числе вопросы определения содержания этой политики и ее реализации на практике.

- Руководство по управлению государственными расходами Всемирного банка (1998 г.) содержит всеобъемлющие рекомендации в отношении болышинства аспектов управления публичными финансами и реализации бюджетных реформ в странах с переходной и развивающейся экономикой.

- Болышая работа была также проведена МВФ и Всемирным банком по консультированию отдельных стран в ходе работы и переговоров в рамках статьи IV, проектов технического содействия Всемирного банка и в рамках текущих контактов со странами - членами этих двух международных финансовьх организаций (МФО).

- Руководство ОЭСР (разработанное Р. Алленом и Д. Томмаси) содержит подробные руководящие указания, направленные на оказание содействия странам с переходной экономикой в переходе к современным методам управления общественными финансами.

- Управление государственными расходами АзБР(С. Скьяво-Кампи и Д. Томмаси, 1999 г.) является еще одним источником подробных методических рекомендаций.

- Руководство по надтежащей практике министерства Великобри- 
тании по международному развитию, а также источники других доноров содержат рекомендации, представляющие интерес для развивающихся стран, где техническое содействие и финансовая помощь играют особенно важную роль.

- Национальные Кодексы надлежащей практики, например применяемое в Великобритании «золотое правило» в отношении осуществления заимствований только для финансирования инвестиций (в среднем, с учетом цикличности экономического роста, общий объем чистых заимствований не может превышать общий объем инвестиций)

Г. Инструменты мониторинга и оценки

- Доклады о соблюдении стандартов и кодексов (ДССК) разработаны МВФ и Всемирным банком в рамках программы с определенными приоритетами для оценки как отдельно выбранных стран, так и различных стандартов и кодексов, соблюдение которых подлежит анализу. Кодекс надлежащей практики по обеспечению прозрачности в бгджетно-налоговой сфере МВФ является, таким образом, лишь одним из кодексов по финансовой стабильности, который может подлежать оценке конкретным ДССК. Для оценки соблюдения Кодекса МВФ используется Вопросник МВФ по обеспечению прозрачности в бюджетно-налоговой сфере.

- В рамках совместной донорской программы партнерства «Государственные расходы и финансовая подотчетность» (ГРФП) была разработана система оценки эффективности управления государственными финансами. Она включает: а) набор показателей для измерения и мониторинга результатов деятельности национальньх систем управления публичными финансами, характера процессов и функционирования институтов в этой сфере и б) формат отчета, содержащий краткую оценку достижений страны на основе анализа показателей, а также описывающий уже проведенные и осуществляемые на данный момент мероприятия по реализации реформ. Показатели оценивают достоверность, комплексность и прозрачность бюджета, качество процессов, протекающих во всех фазах бюджетного цикла, а также степень вовлеченности доноров. Первые оценки уже были проведены. Система разработана для стран с развивающейся и переходной экономикой, однако она может иметь и более широкое применение.

- Система ОЭСР PUMA и система OЭСP/EC SIGMA также могут быть использованы в данной области, последняя в числе прочего предусматривает проведение соответствующей оценки, проводимой пред- 
ставителями высших финансовых органов других стран-партнеров ${ }^{3}$.

Описанные выше источники представляют собой обширный набор хорошо обоснованных и практически ценных материалов. Однако в них отсутствуют общность подхода, необходимая консолидация и авторитетность, которые бы позволили повысить значение рассматриваемых принципов, сделать их более ясными, понятными и легкими для использования, а также придать им новое звучание.

В частности, Кодекс МВФ и Оптимальная практика ОЭСР акцентируют особое внимание на обеспечении прозрачности в бюджетноналоговой сфере как фактора эффективного и ответственного управления публичными финансами. Два других аспекта (устойчивость публичных финансов и эффективность бюджетно-налоговой политики) в кодексах не раскрываются, за исключением общих вопросов аудита, рассматриваемых в Лимской декларации.

В результате многие аспекты общепризнанной надлежащей практики управления публичными финансами не получили отражения в официально согласованных кодексах. Эти пробелы включают в себя такие имеющие важнейшее значение вопросы, как целесообразность наличия бюджетно-налоговых правил стабилього и устойчивого управления бюджетными расходами и обязательствами, а также среднесрочное (многолетнее) бюджетное планирование.

В отношении обеспечения прозрачности в бюджетно-налоговой сфере существуют расхождения в положениях Кодекса МВФ и Оптимальной практики ОЭСР. Причиной этого является попьтка провести разграничение между базовыми и более продвинутыми принципами с учетом того, что многие страны все еще работают над реализацией первых, в то время как другие государства без особых проблем могут добиться соблюдения более высоких стандартов. При этом наличие единой системы, принимающей во внимание существование различий между базовым и более продвинутым уровнями надлежащей практики, могло бы помочь различным странам осуществлять более целенаправленные и последовательные шаги в этой области.

Реализация уже принятых документов по лучшей (надлежащей) практике имеет определенные трудности, особенно для стран с развивающейся и переходной экономикой, в том числе для России. Одна из проблем заключается в определении единой системы принципов, на основе которых могли бы проводиться бюджетные реформы. Остастся до ${ }^{3}$ http://www.prime-tass.ru/analytics/files/documents/minfing8.pdf. 
конца неясным, в чем заключаются эти принципы, каков накопленный опыт и уроки их реализации, какие источники заслуживают первостепенного внимания и в чем состоят тенденции их развития в менягщихся условиях.

Для решшения этих проблем «Группа восьми» обсудила по инициативе России и в основном одобрила следующий базовьй перечень принципов (компонентов) эффективного и ответственного управления публичными финансами:

1) финансовая (налогово-бгджетная) прозрачность;

2) стабильность и долгосрочная устойчивость бюджетов;

3) эффективная и справедливая система межбюджетных отношений;

4) консолидация бюджета и бюджетного процесса;

5) среднесрочное финансовое планирование;

6) бюджетирование, ориентированное на результаты;

7) эффективный финансовьй контроль, отчетность и мониторинг.

В то же время следует отметить, что в настояшее время бюджетные системы России и развитых рыночных стран различаются как по показателям, характеризующим собственно бюджетное устройство этих стран, принщипам формирования доходной части бюджста, объемам и направлениям распределения бюджетных расходов, так и по принципам бюджетной отчетности, степени открытости бюджета и т.д.

Существуют также различия в правовых и институционалыных условиях определения самих приоритетов бюджетной политики, процедурах проведения их в жизнь. Все это означает, что гармонизация бюджетной политики России в соответствии с мировым опытом может потребовать болышей работы по согласованию этих процедур и институтов, чем это представляется на данном этапе. Хотя усилия для ускорения этого процесса Россия прилагает значительные.

\section{International Principles for Good Governance of Public Finance. New Initiative of Russia (Summary)}

Tszyan V.Sh.*

Due to globalization of the economy good governance of public finance is

${ }^{*}$ Tszyan V.Sh - Ph.D. student, MGIMO-University. 
of fundamental importance for all countries to ensure the sustainability of national budget and financial systems, as well as mutual financial security and sustainable economic growth. This article considers the key issues involved in and the work done up to now to spread and apply best practice in management of public finances. Article also highlights the need for further work and the main areas for continuation of work with the aim of improving mutual financial security and creating more favorable conditions for sustainable growth worldwide. Taking account of the collective experience gained in public finance in recent years, including the results of budget reforms, this article presents for discussion generally accepted, dynamic and flexible principles, standards and criteria for good governance of public finance.

The article examines the following basic list of principles (or components) of good governance of public finance:

1. fiscal transparency;

2. stability and long-term sustainability of budgets;

3. an effective and equitable system of inter-budgetary relationships;

4. an integrated budget and budget process;

5. medium-term financial planning;

6. result-oriented budgeting; and

7. effective financial control, reporting and monitoring.

The article stresses that in the last 15-20 years approaches to all these issues have received much attention both nationally and internationally. Farreaching reforms in methods of budget management have been undertaken in a large number of countries, including the developed and developing ones as well as countries in transition. 